\title{
On the path to reach the SDG targets: Decreasing maternal and child mortality in South Africa
}

Despite some progress made between 2008 and 2015, South Africa (SA) did not reach the Millennium Development Goals targets for maternal and child health by the end of 2015. We cannot fail to reach the Sustainable Development Goals (SDGs) and targets. This means that we need to provide robust benchmarks and specific plans for the 2017 - 2030 period and implement the plans with a great sense of urgency.

This series of papers on maternal, neonatal and child health provides an update on the progress to date and highlights critical issues that we need to attend to immediately. The Global Strategy for Women's, Children's and Adolescents' Health 2016 - $2030^{[1]}$ provides guidance on the key issues that countries should focus on, with an emphasis on interventions to ensure greater survival rates, the importance of thriving, as well as the need for transformation of the enabling environment.

SA has signed up to the Global Strategy as well as the SDGs. The Global Strategy's three objectives of survive, thrive and transform are underpinned by a range of action areas: country leadership; financing for health; health system resilience; individual potential; community engagement; multi-sectoral action; innovation and research; and accountability for resources, rights and results. We should therefore read the series of papers in this supplement with these objectives and action areas in mind as well as the targets set in the SDGs.

There are 7 papers in this series. The first $\mathrm{t}^{[1}$ deals with the progress made in reducing institutional maternal mortality, i.e. mortality after admission to a health facility. While we have considerable data and knowledge of institutional maternal mortality through the work of the National Committee for Confidential Enquiry into Maternal Deaths (NCCEMD), we have a paucity of information on maternal deaths that occur outside health facilities, which is estimated to add about $20 \%$ additional deaths to those that are recorded in health facilities. This is an area that we need to address with a greater sense of urgency.

The second paper ${ }^{[\mathrm{l}}$ addresses neonatal mortality after admission to a public health facility using data collated by the National Perinatal Morbidity and Mortality Committee (NaPeMMCo). Similar to the data on maternal mortality, we have little information on neonatal deaths that occur outside health facilities. We need greater community involvement as well as to strengthen our community-based health services to generate these data and intervene to reduce the number of these deaths. This is true for all maternal, neonatal and child deaths that take place outside health facilities. The third paper ${ }^{[1}$ focuses on under- 5 mortality using data collated by the Committee on Morbidity and Mortality in Children under 5 years (CoMMiC).

The three ministerial committees, which prepare annual and triennial reports, have made a significant contribution to understanding the causes of maternal, neonatal and under-5 mortality and in making recommendations to the Minister of Health. By requesting their participation in this series, we hoped that their insights would reach a wider audience so that we can be well on the path to meeting the targets of the SDGs.

In their paper on maternal mortality, Moodley et al. ${ }^{[2]}$ document the impressive annual decline in the institutional maternal mortality rate from a peak of 189 per 100000 in 2009 to 135 per 100000 in 2016. This means that in 2016 there were around 400 fewer maternal deaths compared with 2009. The main reason for this was the large-scale reduction in deaths owing to HIV infection as a result of the success of the HIV antiviral treatment programme in pregnancy and beyond. ${ }^{[2]}$ After additional training in the essential steps in the management of obstetric emergencies was provided, there was also a decline in deaths owing to obstetric haemorrhage between 2015 and 2016. However, more needs to be done to reduce deaths owing to pregnancy-related hypertension and it is hoped that the introduction of additional antenatal visits (increased from 5 to 8 visits following new WHO guidelines) will assist in this regard. However, there is still much to do to achieve the SDG target of 70 per 100000 by $2030 .{ }^{[3]}$ Every manager in the healthcare system working with communities must be supported to redouble efforts to reduce maternal mortality. This includes the provision of good quality sexual and reproductive health services, ensuring early antenatal care attendance and safe delivery.

Neonatal mortality contributes about one-third of under-5 mortality in SA. Rhoda et al. ${ }^{[4]}$ show the slow decline in the neonatal mortality rate over the past 15 years. Even though SA is very close to the SDG target of 12 neonatal deaths per 1000 live births, we should be doing better as a middle-income country and experts are of the opinion that roughly $50 \%$ of all neonatal deaths in SA are avoidable. According to NaPeMMCo, the key causes of neonatal mortality continue to be asphyxia, prematurity and infections. A focus on training in the Helping Babies Breathe programme will assist in reducing deaths from asphyxia and reducing teen pregnancies will reduce deaths related to prematurity. An area for additional focus is the high rate of stillbirths. Some of these issues relate to intrapartum care which emphasises the need for midwives, obstetricians and gynaecologists to work very closely with neonatologists and paediatricians.

In their paper, Bamford et al. ${ }^{[5]}$ demonstrate the remarkable fall of in-patient mortality rates (around $40-50 \%$ ) for three of the most important causes of mortality in children under 5 years of age, i.e. pneumonia, diarrhoea and malnutrition. Similar to its impact on maternal mortality, the contribution of HIV/AIDS to under-5 mortality has declined significantly in the past few years but it remains high. Although we are unable to precisely quantify the numbers of reduced deaths owing to HIV, we can quantify the success of the prevention of mother-to-child transmission (PMTCT) programme, which is shown in the paper on PMTCT. Notwithstanding these dramatic improvements, the authors make the point that SA has a much higher child mortality rate than comparable middle-income countries such as Brazil and Mexico. ${ }^{[6]}$ Bamford et al. ${ }^{[6]}$ also suggest a number of interventions (e.g. increased exclusive breastfeeding, and greater access to water and sanitation), which would further reduce fatality rates from these diseases.

In the paper on improvements in child mortality, McKerrow et al ${ }^{[7]}$ highlight the need for improved data quality with which to quantify and measure child deaths. Part of the data problem is that as many as half of all deaths during the post neonatal period occur out of hospital and accurate population metrics are dependent on all child deaths being accurately reported to the Department of Home Affairs. McKerrow et al. ${ }^{[7]}$ highlight the importance of 
focusing on trends at the provincial level - one might add district and facility levels. There is significant variation in mortality rates across provinces, with the Western Cape usually having the lowest mortality rates. It is unacceptable, in our quest for equity in outcomes, that the Free State has double the under- 5 mortality rate (49.6/1 000 live births) compared with the Western Cape's 24/1 000 live births.

Much of the improvements in maternal, neonatal, child and in-patient mortality have resulted from improvements in the quality of care. Previous improvements in the prevention of mother-to-child transmission of HIV (PMTCT) have been well documented. ${ }^{[8-10]}$ In their paper, Goga et al. ${ }^{[1]}$ show how there have been further decreases in the rate of early (in utero) transmission of HIV from mother to child. Improvements have occurred as a possible result of use of ward-based outreach teams and community caregivers to trace HIV-exposed infants and connect mothers to care. Continuous quality improvement (CQI) processes within facilities and districts have also helped decrease transmission rates. The introduction of birth testing and early initiation on atiretroviral treatment of infants that test HIV-positive, as well as ensuring that HIV-positive mothers are virally suppressed throughout the breastfeeding period, will also go a long way to reduce mother-tochild transmission of HIV. To quality for elimination, we need to reach the WHO/UNICEF goal of $<50$ paediatric HIV infections per 100000 live births.

Other examples in quality improvement are shown by Bhardwaj et al., ${ }^{[12]}$ who used three case studies i.e., training in essential steps in managing obstetric emergencies (ESMOE), management of undernutrition in young children and strengthening of exclusive breastfeeding to illustrate how improved quality of care and coverage achieved better health outcomes for maternal and child mortality. Lastly, but not least, Feucht et al., ${ }^{[13]}$ demonstrated through a number of examples, that the district clinical specialist teams deployed in districts around the country to improve clinical governance, have impacted on a range of practices that are linked to improved care for maternal and child patients. ${ }^{[13]}$

Clearly, SA has done much to improve maternal and child health over the last decade and is well on track to achieve the SDGs for neonatal mortality. However, as a middle-income country SA should be doing better. The HIV epidemic has taken its toll but increasingly is being brought under control with consequent declines in both maternal and child mortality. To go the next mile will require much greater consistency in improvement of quality throughout the health system. These improvements must be accompanied by strengthened community systems and greater involvement of men as partners, both in the context of maternal health as well as in the health of their children. In this context is it worrying that in the recent STATSSA report, ${ }^{[14]}$ shows that there were 1444 births to children 10 - 14 years old with a further 107730 births to adolescents aged 15 - 19 years old! The quest for universal health coverage as reflected in the national health insurance policy must be matched by quality improvements in every home, community and health facility, with each individual playing his/her part to achieve this goal.
Y Pillay

National Department of Health, Pretoria, South Africa

\section{P Barron}

School of Public Health, University of the Witwatersrand, Johannesburg, South Africa pbarron@iafrica.com
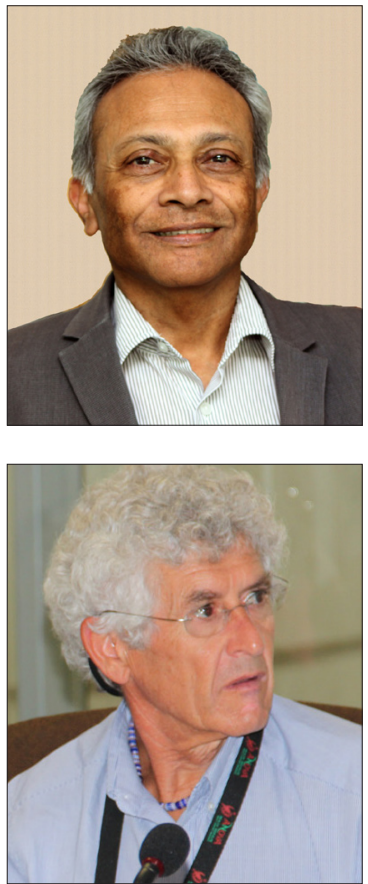

1. World Health Organization. The Global Strategy for Women's, Children's and Adolescents' Health (2016 - 2030). Geneva: WHO, 2015. http://www.who.int/life-course/partners/global-strategy/ewecglobalstrategyreport-200915.pdf?ua=1 (accessed 1 October 2017).

2. Moodley J, Fawcus S, Pattinson R. Improvements in maternal mortality in South Africa. S Afr Med J 2018;108(3 Suppl 1):S4-S8. https://doi.org/10.7196/SAMJ.2018.v108i3.12770

3. United Nations. Sustainable Development Goals. United Nations 2015. https://www.un.org/pga/wp3. United Nations. Sustainable Development Goals. United Nations 2015. https://www.un.org/pga/wp-
content/uploads/sites/3/2015/08/120815_outcome-document-of-Summit-for-adoption-of-the-postcontent/uploads/sites/3/2015/08/120815_outcome-document-o

4. Rhoda N, Velaphi S, Gebhardt G, Kauchali S, Barron P. Reducing Neonatal Deaths in South Africa: Progress and challenges. S Afr Med J 2018;108(3 Suppl 1):S9-S16. https://doi.org/10.7196/SAMJ.2018. v108i3.12804

5. Bamford L, Barron P, Kauchali S, Dlamini N. In-patient case fatality rates improvements in children under five: Diarrhoeal disease, pneumonia and severe acute malnutrition. S Afr Med J 2018; 108(3 Suppl 1):S33-S37. https://doi.org/10.7196/SAMJ.2018.v108i3.12772

6. UNICEF. Countdown to 2015 maternal newborn and child survival: A Decade of Tracking Progress for Maternal, Newborn and Child Survival: The 2015 Report. New York: UNICEF, 2015. http:// countdown2030.org/documents/2015Report/Countdown_to_2015_final_report.pdf (accessed 24 September 2017).

7. Bamford L, McKerrow NH, Barron P, Aung Y. Child mortality in South Africa: Fewer deaths but better data are needed. S Afr Med J 2018;108(3 Suppl 1):S25-S32. https://doi.org/10.7196/SAMJ.2018. v108i3.12779

8. Barron P, Pillay Y, Doherty T, et al. Eliminating mother-to-child HIV transmission in South Africa. Bull World Health Organ 2013;91:70-74. https://doi/10.2471/BLT.12.106807

9. Bhardwaj S, Barron P, Pillay Y, et al. Elimination of mother-to-child transmission of HIV in South 9. Bhardwaj S, Barron P, Pillay Y, et al. Elimination of mother-to-child transmission of HIV in South
Africa: Rapid scale-up using quality improvement. S Afr Med J 2014;104(3 Suppl 1):239-243. https:// doi.org/10.7196\%2FSAMJ.7605

10. Sherman G, Lillian R, Bhardwaj S, Candy S, Barron P. Laboratory information system data demonstrate successful implementation to the prevention of the mother-to-child transmission programme in South Africa. S Afr Med J 2014;104(3 Suppl 1):235-238. https://doi.org/10.7196\%2FSAMJ.7598

11. Goga A, Chirinda W, Ngandu NK, et al. Closing the gaps to eliminate mother-to-child transmission (MTCT) of HIV in South Africa: Understanding MTCT case rates, factors that hinder the monitoring and attainment of targets, and potential game changers. S Afr Med J 2018;108(3 Suppl 1):S17-S24. https://doi.org/10.7196/SAMJ.2018.v108i3.12817

12. Bhardwaj S, Pattinson R, Kauchali S, et al. Implementation of strategies to improve programme effectiveness lead to an improvement in maternal and child health outcomes in South Africa. S Afr Med J 2018;108(3 Suppl 1):S44-S49. https://doi.org/10.7196/SAMJ.2018.v108i3.12812

13. Feucht U, Marshall C, Kauchali S, et al. Innovations in the clinical care of mothers and children in 3. Feucht U, Marshall C, Kauchali S, et al. Innovations in the clinical care of mothers and children in
South Africa: The contribution of district clinical specialist teams. S Afr Med J 2018;108(3 Suppl 1): South Africa: The contribution of district clinical specials

14. Statistics South Africa (StatsSA). Recorded Live Births 2016. Pretoria: StatsSA, 2017. http://www. statssa.gov.za/publications/P0305/P03052016.pdf (accessed 1 October 2016).

S Afr Med J 2018;108(3 Suppl 1):S1-S2. DOI:10.7196/SAMJ.2018.v108i3.12901 